https://doi.org/10.52288/jbi.26636204.2020.01.01

\title{
基于 CCSI 模型对微信小程序的满意度影响因素研究 Satisfaction Survey of WeChat Mini Program Based on CCSI Model
}

\author{
吴全成 ${ }^{*}$ \\ Quan-Cheng Wu \\ 张荣浅 ${ }^{2}$ \\ Rong-Fong Chang
}

\section{摘要}

微信小程序的研究当前在国内偏重于商业化、新零售等, 而在国外并无相关研究, 在顾客满意度方面的研究则呈现为一片空白。本文在研究方法上采用文献分析法与 问卷调查法, 以微信小程序用户为研究对象, 用户满意度的相关理论及中国顾客满意 度模型 (CCSI) 为依据, 先从微信小程序发展背景及现状进行分析, 并结合用户满 意度调查分析, 运用 SPSS 24.0 软件对收集到的数据进行统计分析和模型验证, 找出 当前微信小程序用户满意度各项分析维度存在的差异, 再对具体模型进行修正, 并对 其提出建议。

关键词：微信小程序、顾客满意度、中国顾客满意度模型

\begin{abstract}
At present, WeChat Mini Program focuses on commercialization and new retail sales in China, but there is no related research in foreign countries. The research on customer satisfaction is blank. This paper adopts literature analysis method and questionnaire survey method in the research method. Based on the user of WeChat Mini Program, the related theory of user satisfaction and the Chinese Customer Satisfaction Model (CCSI) are applied. Background and status quo of WeChat Mini Program development are analyzed first along with the user satisfaction survey analysis and SPSS 24.0 software to analyze and validate the collected data. Differences among the analysis dimensions of user satisfaction of the WeChat Mini Program are found to modify the model and suggestions are proposed thereafter.
\end{abstract}

Keywords: WeChat Mini Program, Customer Satisfaction, China Customer Satisfaction Model (CCSI)

\section{1. 前言}

微信小程序是一个新兴概念, 2017 年才被腾讯高级副总裁张小龙正式提出并上 线。经过一年多的发展, 截止 2019 年 4 月，微信小程序已经发展成为微信的三大支 柱之一，其所提供的收益以及与各类商户的合作等，使得腾讯已经将“互联网+”这个 概念深入贯彻于微信的每一个方方面面。

微信小程序的应用可以接触到各行各业, 任何个人或组织都能申请注册并且开 发小程序。同时, 小程序的应用也包括了游戏、商业、应用等各方面, 其带来了各种

1 厦门大学嘉庚学院国际商务学院教授 johnwu300@xujc.com*通讯作者

2 厦门大学嘉庚学院国际商务学院本科生 
各样的就业机会, 产生的利益更是让人无法忽视。微信小程序在我国的未来是显而易 见的, 并且依托于微信的庞大用户, 其用户体量已经通过微信的用户群体飞速的转化 成自己的用户。但是由于发展时间尚短, 目前学术界对微信小程序的研究重点均在其 “未来会带来的变化上”，比如其对新零售的影响、其对当前企业在线上线下结合交互 的影响、其未来可能会偏向或侧重的发展方向等。然而, 微信小程序在顾客满意度这 一方面的研究是空白的, 发展如此迅速的微信小程序难道仅仅是依托于微信本身的 自带流量? 在其它方面, 比如用户体验等就没有其独到的、可圈可点的地方值得我们 去研究和探讨吗?

学术界对小程序满意度研究关注的时间非常短, 然而在其它领域的发展速度却 非常迅速。截止 2019 年 4 月为止, 微信小程序依托微信的庞大用户基础, 通过前期 的小游戏宣传手段的导流, 迅速将大部分的微信用户转化为切实的小程序用户。微信 小程序的出现及抢占市场迅雷不及掩耳, 在当下市场上并没有与其类似的竞争对手 出现, 成为市场上消费的垄断者。

\section{2. 文献综述}

\section{1 顾客满意度的模型和实证研究}

\subsection{1 顾客满意度的相关理论模型}

我国于 2000 年 6 月开始研究属于我国的满意度模型课题, 该课题开放了符合我 国当代国情且具备世界先进的中国顾客满意度指数(China Customer Satisfaction Index, 简称 CCSI) 的测量模型 ${ }^{3}$ (如图 1)。

中国顾客满意度指数 (CCSI) 模型是以 CSD 机制为理论基础, 有 6 个结构变量, 即预期质量、感知价值、感知质量、品牌信息、顾客满意度和顾客忠诚。CCSI 模型 和 ACSI 模型对比, 增加了品牌信息, 去掉了顾客抱怨变量。根据以上的分析, CCSI 模型综合了美国用户满意度指数方法, 最适合我国的各行业特点; 无论是研究消费行 为还是研究市场营销, 所研究地区的特点和具体情况是测评的关键所在, 因此基于以 上考虑, 本文的研究主要采取 CCSI 模型进行验证。

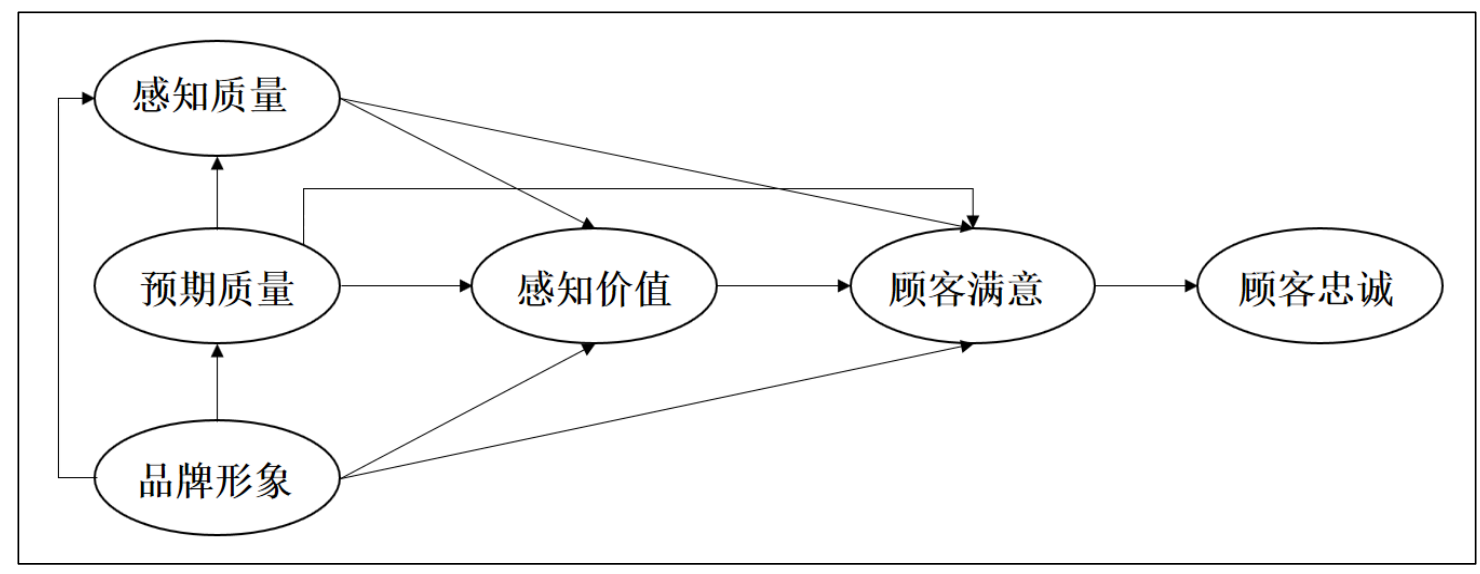

数据源：作者整理，2019 年 4 月

图 1. 中国的顾客满意指数基本模型 $(\mathrm{CCSI})^{4}$

3 佚名（2005）。中国标准化研究院顾客满意度测评中心成立。中国防伪，6，62-62。

4 汤万金、咸奎桐、郑兆红、康键（2009）。顾客满意测评理论与应用。北京; 中国计量出版社。 


\subsection{2 中国顾客满意指数模型(CCSI)的相关实证研究}

由于中国顾客满意度指数模型(CCSI)的研究时间较短, 对其研究应用仍多处于借 鉴和参考阶段，如表 1 所示:

表 1. 实证研究文献综述

\begin{tabular}{cl}
\hline 学者及年代 & \multicolumn{1}{c}{ 实证行业 } \\
\hline 孙静芬 $(2004)$ & 在 CCSI 基础上, 构建手机行业顾客满意度评价指标体系 ${ }^{5}$ \\
蒋伟伟 $(2007)$ & 顾客对搜索引擎的重点关注 (Baidu 和Yahoo $)^{6}$ \\
金宁 $(2009)$ & 运用 CCSI 模型分析了乘客满意度的影响因素 ${ }^{7}$ \\
吴绍玉 $(2012)$ & 在 CCSI 基础上, 构建地铁乘客满意度指数 MPSI $^{8}$ \\
余庆 $(2012)$ & 晨希快递公司顾客满意度测评指标 ${ }^{9}$ \\
赵蓉辉 $(2014)$ & CCSI 基础上, 建立 45 个四级指标的酒店文化评价指标体系 ${ }^{10}$ \\
\hline
\end{tabular}

数据源：作者整理，2019 年 4 月

\section{3. 研究方法}

\section{1 研究模型与研究假设}

中国顾客满意指数模型 (CCSI) 是建立在顾客在消费与购买的心理体验的基础上, 根据满意度形成的因果关系而建的。通过关于顾客满意度模型的文献综述, 结合前人 的研究成果, 本文以中国顾客满意指数模型 (CCSI) 为基础, 从消费者的角度出发, 针对微信小程序的顾客忠诚度进行验证，该模型包括六个潜变量：

\section{(1) 微信小程序品牌形象}

品牌形象与品牌相辅相成, 形象体现了品牌的实力和本质。品牌形象是用户对所 知品牌的一种认知及联想，这情况正是各个品牌使用者的所属行为所造成。用户对品 牌形成联想既可以通过企业掌控的管道获得, 也可以通过非企业掌控的管道获得 ${ }^{11}$ 。

\section{(2) 微信小程序预期质量}

微信小程序预期质量即顾客对微信小程序所提供服务预期的满意度。用户在获 得或使用一个产品之前, 都会对产品所能带给用户的体验、服务或者能达到的目的有 一个心理预期，预期服务质量是影响顾客对整体服务质量感知的重要前提 ${ }^{12}$ 。

5 孙静芬（2004）。基于 CCSI 模型的手机行业 CSI 测评与改进研究（未发表之硕士论文）。南京 市：南京理工大学。

6 蒋伟伟 (2007) 。基于 CCSI 模型的搜索引擎评价研究。情报科学, 11，1659-1663。

7 金宁（2009）。基于乘客满意度的城市轨道交通服务质量评价（未发表之硕士论文）。吉林省： 吉林大学。

8 吴绍玉（2012）。基于 CCSI 的 T 市地铁乘客满意度研究（未发表之硕士论文）。天津市：天津 大学。

9 余庆（2012）。晨希快递公司顾客满意度测评及提升研究（未发表之硕士论文）。湖南省：中南 大学。

10 赵蓉辉（2014）。基于酒店文化评价指标的顾客满意度测评研究（未发表之硕士论文）。湖南 省：湘潭大学。

11 李小军（2006）。企业品牌形象塑造研究（未发表之硕士论文）。湖南省：湘潭大学。

12 董麦生（2013）。广州市房地产商住项目顾客满意度影响因素浅析（未发表之硕士论文）。广州 市：华南理工大学。 


\section{(3) 微信小程序感知质量}

所谓微信小程序感知质量, 是顾客自己在使用微信小程序想要达到的目的, 以及 需要被满足的需求状况的一种体现。在购买或使用一款产品前, 用户都会主动获取关 于目标产品的信息，价值越大、价格越高的产品需要的信息就越多，反之亦然。因此 对企业营销活动, 最重要的任务是通过不同途径来提高消费者对产品的感知质量 ${ }^{13}$ 。

\section{(4) 微信小程序感知价值}

消费者希望在交易的过程中实现自身的价值。消费者价值的本质是消费者感知， 即消费者对与微信小程序交互过程和结果的主观感知, 后者是指企业认为自己的服 务或产品可以为消费者提供的价值, 属于企业内部认知导向; 而前者是指消费者对企 业所提供的服务或产品的价值判断, 属于外部消费者认知导向 ${ }^{14}$ 。

\section{(5) 微信小程序顾客满意}

微信小程序顾客满意, 是以微信小程序用户知觉到的产品实际状况, 和用户的预 期相比较来决定的。如果微信小程序的实际使用体验等各方面不符合用户的要求, 则 用户会感到对其不满意; 如果实际体验正如其预期的一样, 则用户感到满意; 如果实 际体验超过了用户一开始的设想, 则用户感到非常满意。

\section{（6）微信小程序顾客忠诚}

微信小程序顾客忠诚, 是指顾客对微信小程序的产品或服务的依恋或爱慕的感 情, 它主要通过用户的偏好度、使用情况和对其的看法表现出来。其中偏好度表现为 用户对其各方面形象、使用的认可; 使用情况表现为使用者愿意反复使用且不会使用 其它同类型产品; 看法偏向则表现为用户对其往后的更新换代、版本体验升级的期待 等。因此, 本研究建议假设如下：
$\mathrm{H} 1 ：$ 品牌形象对感知质量呈现显著影响
$\mathrm{H} 2$ ：品牌形象对预期质量呈现显著影响
$\mathrm{H} 3$ ：品牌形象对感知价值呈现显著影响
H4：品牌形象对顾客满意呈现显著影响
$\mathrm{H} 5$ ：预期质量对感知价值呈现显著影响
H6：预期质量对感知质量呈现显著影响
$\mathrm{H} 7$ ：预期质量对顾客满意呈现显著影响
H8：感知质量对感知价值呈现显著影响
H9：感知质量对顾客满意呈现显著影响
H10：感知价值对顾客满意呈现显著影响
H11：顾客满意对顾客忠诚呈现显著影响

\section{2 问卷设计}

在实际调查的研究过程中, 使用 5 级李克特量表, 从 1 到 5 态度的依次发生改 变。1 表示非常不同意，2表示不同意，3表示一般，4表示同意，5表示非常同意。 为了保障对问卷相关问题项修改的合理以及调查问卷的整体质量, 通过与微信小程

13 王海忠、王晶雪、何云 (2007)。品牌名、原产国、价格对感知质量与购买意向的暗示作用。南 开管理评论, $6,19-25+32$ 。

14 韩春鲜（2015）。旅游感知价值和满意度与行为意向的关系。人文地理, 30(3), 137-144+150。 
序用户进行访谈沟通, 对表述不清楚或者难以理解的问题项进行语句调整, 量表具体 问题和内容如下表 2 。

表 2. 基于 CCSI 模型对微信小程序的满意度影响因素研究问卷

\begin{tabular}{|c|c|}
\hline 维度 & 题 \\
\hline \multirow{4}{*}{ 品牌形象 } & 1.微信小程序本体品牌标志（即微信）容易辨别 \\
\hline & 2.对用户承诺提供的信息服务能准确兑现 \\
\hline & 3.保护用户权益, 未经授权不使用用户信息 \\
\hline & 4.微信小程序的品牌形象值得信赖 \\
\hline \multirow{5}{*}{ 预期质量 } & 1.使用微信小程序给您带来的体验超过了预期 \\
\hline & 2.使用微信小程序给您带来的便利超过之前的预期 \\
\hline & 3.微信小程序提供的服务质量很高 \\
\hline & 4. 微信小程序提供的各方面服务都非常好 \\
\hline & 5. 总体来说, 您对微信小程序的期望在使用过程中基本得到满足 \\
\hline \multirow{5}{*}{ 感知品质 } & 1.微信小程序操作接口简单流畅 \\
\hline & 2.微信小程序的支付系统便捷完善 \\
\hline & 3.使用微信小程序可以使您更便利地获得您所需的服务 \\
\hline & 4. 您在使用微信小程序获得所需服务的过程总体是安全的 \\
\hline & 5.您使用微信小程序时, 没有遇到过软件崩溃或者闪退的情况 \\
\hline \multirow{5}{*}{ 感知价值 } & 1.微信小程序可以让您在获得相同的服务时更加便利 \\
\hline & 2.微信小程序可以让您花费同样的钱获得更好的服务 \\
\hline & 3.微信小程序可以让您在获得相同的服务时更加省时 \\
\hline & 4. 微信小程序可以让您花更少的时间查找到喜欢的产品及服务 \\
\hline & 5.相比使用其他服务 APP , 你更愿意花费同样的时间和金钱在微信小程序上 \\
\hline \multirow{3}{*}{ 顾客满意度 } & 1.您对微信小程序总体上是满意的 \\
\hline & 2. 微信小程序的使用体验达到了您的预期 \\
\hline & 3. 您愿意给微信小程序一个很高的评价 \\
\hline \multirow{3}{*}{ 顾客忠诚度 } & 1.您会继续使用微信小程序 \\
\hline & 2. 您会向您的亲朋好友推荐微信小程序 \\
\hline & 3.您愿意向别人宣传微信小程序 \\
\hline
\end{tabular}

数据源：作者整理，2019 年 4 月

\section{3 调查方案}

根据 CCSI 模型研究设计出的调研问卷, 通过在线与线下的发放途径给使用过微 信小程序的调研人群。在线问卷主要通过卷星小程序进行发放及数据收集整理, 具体 
实现方法为: 通过参考肖有康 ${ }^{15}$ 设计问卷、陈青 ${ }^{16}$ 的论文设计问卷、王晨亮 ${ }^{17}$ 的研究设 计问卷, 借鉴和参考他们的问卷进行反复的修改, 并将修改过后问卷的最终版本发布 在问卷星上。问卷命名为《基于 CCSI 模型对微信小程序满意度影响因素研究调查问 卷》, 在线问卷发放的途径多为微信、QQ 等在线平台, 面向全地区的不同职业、年 龄层的受访人群进行, 于 2019 年 3 月下旬通过在线发放的形式, 成功收集到来自全 国各地的回馈问卷 506 份, 其中有效问卷 506 份; 线下的问卷发放的途径多为在学 校、厦门市区等地发放, 面向不同职业、年龄层的受访人群进行, 于 2019 年 3 月下 旬发放, 成功收集到回馈问卷 34 份, 其中有效问卷 34 份。在线与线下共计收获回 馈问卷 540 份, 其中有效问卷 540 份。

\section{4. 资料分析}

\section{1 描述性统计分析}

\subsection{1 样本分布情况}

本部分内容主要包括微信小程序用户的基本信息、微信小程序使用情况的描述 性统计分析两个部分。第一部分分析结果如表 3 所示:

本研究的样本分布为女性 $62.04 \%$, 男性 37.96\%。年龄分布方面, 18-25 岁的群 体占据了样本的 $73.89 \%$, 样本群体呈现年轻化的趋势, 偏年轻化的受众群体与微信 给出的 2018 年用户相关数据的情况差不多。在职业和受教育程度两个方面, 因为在 线问卷发放的局限性, 使得样本当中在校学生占了比较大的群体比例, 被调研人群受 教育程度普遍较高, 大学本科学历以下人群只占了样本的 $21.3 \%$ 咗个人月收入方面, 以 2,000 元及以下和 2,001-4,000 元的人数居多, 两部分人数占总样本的 $66.11 \%$ 。

\subsection{2 微信小程序使用情况的统计分析}

除开人口统计学的特征相关问题之外, 本研究还在问卷当中设置了微信小程序 的使用频率问题，统计分析如下表 4 所示。由收集的问卷数据分析得知，微信小程序 的用户使用微信小程序处于较极端状态，有 $42.78 \%$ 的人偶尔会临时使用到小程序， 而仅有 $28.7 \%$ 的人几乎每天都在用。但从整体来看, 有 $57.22 \%$ 的人每周至少用 $1-2$ 次 小程序, 从样本来看, 这是偏乐观的数据, 所以对此进行满意度提高的研究。

\section{2 信度分析}

本文需进行验证的条目共有六个, 分别是品牌形象、预期质量、感知质量、感知 价值、顾客满意和顾客忠诚, 六个维度检测完成后对问卷整体信度进行检测。经过分 析后的测量结果如表 5 。数据结果显示, 问卷的品牌形象、预期质量、感知质量、感 知价值、顾客满意度和顾客忠诚度的一致性 Cronbach's Alpha 系数都非常高, 并且问 卷整体的系数也非常高, 均高于 0.8 以上;其中品牌形象维度信度最低, 系数为 0.827 , 预期质量维度信度最高, 系数为 0.934 。问卷整体信度也非常高, 系数为 0.972 , 表明 本研究的各个量表的信度以及问卷整体的信度都非常好。

\footnotetext{
15 肖有康（2016）。旅游类手机 APP 用户满意度影响因素实证研究（未发表之硕士论文）。湖北省： 华中师范大学。

16 陈青 (2012) 璂于顾客价值的销售服务顾客满意度测评研究一以汽车 4S 店为例 㖉业经济, 31(7), 94-97。

17 王晨亮（2004）。行业顾客满意度测评理论研究（未发表之硕士论文）。北京市：首都经济贸易大 学。
} 
表 3. 研究样本个人基本信息统计

\begin{tabular}{|c|c|c|c|}
\hline \multicolumn{2}{|c|}{ 人口特征变化 } & 有效百分比\% & $\mathrm{N}$ \\
\hline \multirow{2}{*}{ 性别 } & 男 & $37.96 \%$ & 205 \\
\hline & 女 & $62.04 \%$ & 335 \\
\hline \multirow{7}{*}{ 年龄 } & 18 岁以下 & $1.11 \%$ & 6 \\
\hline & 18-25 岁 & $73.89 \%$ & 339 \\
\hline & 26-30 岁 & $7.78 \%$ & 42 \\
\hline & 31-40 岁 & $8.52 \%$ & 46 \\
\hline & 41-50 岁 & $7.41 \%$ & 40 \\
\hline & 51-60 岁 & $0.74 \%$ & 4 \\
\hline & 60 岁以上 & $0.56 \%$ & 3 \\
\hline \multirow{8}{*}{ 职业 } & 在校学生 & $53.52 \%$ & 289 \\
\hline & 企业职员 & $12.59 \%$ & 68 \\
\hline & 公务员 & $2.22 \%$ & 12 \\
\hline & 事业单位 & $13.70 \%$ & 74 \\
\hline & 自由职业者 & $5.74 \%$ & 31 \\
\hline & 个体商户 & $3.33 \%$ & 18 \\
\hline & 无业/退休人员 & $2.04 \%$ & 11 \\
\hline & 其他 & $6.85 \%$ & 37 \\
\hline \multirow{5}{*}{ 受教育程度 } & 高中及以下 & $10.93 \%$ & 59 \\
\hline & 专科 & $10.37 \%$ & 56 \\
\hline & 本科 & $74.44 \%$ & 402 \\
\hline & 硕士 & $2.96 \%$ & 16 \\
\hline & 博士及以上 & $1.30 \%$ & 7 \\
\hline \multirow{6}{*}{ 个人月收入 } & 2,000 元及以下 & $40 \%$ & 216 \\
\hline & $2,001-4,000$ 元 & $26.11 \%$ & 141 \\
\hline & $4,001-6,000$ 元 & $19.81 \%$ & 107 \\
\hline & $6,001-8,000$ 元 & $7.59 \%$ & 41 \\
\hline & $8,001-10,000$ 元 & $2.96 \%$ & 16 \\
\hline & 10,000 元以上 & $3.52 \%$ & 19 \\
\hline
\end{tabular}

数据源：作者整理， 2019 年 4 月， $\mathrm{N}=540$

表 4. 用户习惯统计分析

\begin{tabular}{cccc}
\hline 问题内容 & 问题选项 & 频次 $(\mathrm{N})$ & 百分比 \\
\hline & 偶尔临时使用 & 231 & $42.78 \%$ \\
& 平均每周 1-2 次 & 79 & $14.63 \%$ \\
您每周使用微信小程序的频率是 & 平均每周 3-5 次 & 75 & $13.89 \%$ \\
& 几乎每天都在使用 & 155 & $28.70 \%$ \\
\hline
\end{tabular}

数据源：作者整理, 2019 年 4 月, $\mathrm{N}=540$ 
表 5. 信度检验

\begin{tabular}{ccc}
\hline 变数 & Cronbach's Alpha & 题目数 \\
\hline 品牌形象 & 0.827 & 4 \\
预期质量 & 0.934 & 5 \\
感知品质 & 0.862 & 5 \\
感知价值 & 0.924 & 5 \\
顾客满意度 & 0.932 & 3 \\
顾客忠成度 & 0.884 & 3 \\
\hline 问卷整体 & 0.972 & 25 \\
\hline
\end{tabular}

数据源：作者整理, 2019 年 4 月

\section{3 效度分析}

效度分析也被称为有效性分析, 根据 $\mathrm{KMO}$ 值可得该结果是否适合做因子分析。 本文需要检测的效度及因子分析部分共有六个。

\subsection{1 品牌形象因子分析}

本文通过因子分析对问卷的有效度进行检验, 由表 6 可知, 品牌形象量表 KMO 为 $0.789(0.7<\mathrm{KMO}<0.8)$, 且 Bartlett's 球形检验卡方值也达显著水平, 分析结果 见下表 6 所示。接着本文对品牌形象量表的 4 个题目进行因子分析后, 由表 7 可知, “品牌形象”的累计解释变异量达 $66.667 \%(>50 \%)$ ) 说明此量表具有很高的解释性。

表 6. 品牌形象量表 $\mathrm{KMO}$ 和 Bartlett's 球形检验

\begin{tabular}{ccc}
\hline $\mathrm{KMO}$ 值 & 0.789 & \\
\hline & 近似卡方值 & 855.658 \\
Bartlett's 球形检验 & 自由度 & 6 \\
& $\mathrm{P}$ 值 & 0.000 \\
\hline
\end{tabular}

数据源：作者整理, 2019 年 4 月

表 7. 品牌形象量表因子分析

\begin{tabular}{cc}
\hline \multicolumn{1}{c}{ 题目 } & 因子负荷量 \\
\hline & 1 \\
1.微信小程序本体品牌标志 (即微信) 容易辨别 & 0.741 \\
2.对用户承诺提供的信息服务能准确兑现 & 0.887 \\
3.保护使用者权益, 未经授权不使用用户信息 & 0.774 \\
4.微信小程序的品牌形象值得信赖 & 0.856 \\
\hline 特征值 & 2.667 \\
解释变异量 $(\%)$ & 66.667 \\
累计解释变异量 $(\%)$ & 66.667 \\
\hline
\end{tabular}

数据源：作者整理，2019 年 4 月

\subsection{2 预期质量因子分析}

本文通过因子分析对问卷的有效度进行检验, 由表 8 可知, 预期质量量表 KMO 为 $0.877(0.8<\mathrm{KMO}<0.9)$, 且 Bartlett's 球形检验卡方值也达显著水平, 分析结果 见下表 8 所示。接着本文对预期质量量表的 5 个题目进行因子分析后, 由表 9 可知, “预期质量”的累计解释变异量达 79.336\%( > 50\%) 说明此量表具有很高的解释性。 
表 8. 预期质量量表 KMO 和 Bartlett's 球形检验

\begin{tabular}{ccc}
\hline KMO 值 & 0.877 & \\
\hline & 近似卡方值 & $2,336.335$ \\
Bartlett's 球形检验 & 自由度 & 10 \\
& $\mathrm{P}$ 值 & 0.000 \\
\hline
\end{tabular}

数据源：作者整理，2019 年 4 月

表 9. 预期质量量表因子分析

\begin{tabular}{lc}
\hline \multicolumn{1}{c}{ 题目 } & 因子负荷量 \\
\hline & 1 \\
1.使用微信小程序给您带来的体验超过了预期 & 0.842 \\
2.使用微信小程序给您带来的便利超过之前的预期 & 0.894 \\
3.微信小程序提供的服务质量很高 & 0.930 \\
4.微信小程序提供的各方面服务都非常好 & 0.892 \\
5.总体来说，您对微信小程序的期望在使用过程中基本得到满足 & 0.894 \\
\hline 特征值 & 3.967 \\
解释变异量 $(\%)$ & 79.336 \\
累计解释变异量 $(\%)$ & 79.336 \\
\hline
\end{tabular}

数据源：作者整理，2019 年 4 月

\subsection{3 感知质量因子分析}

本文通过因子分析对问卷的有效度进行检验, 由表 10 可知, 感知品质量表 KMO 为 $0.855(0.8<\mathrm{KMO}<0.9)$, 且 Bartlett's 球形检验卡方值也显著水平, 分析结果见 下表 10 所示。接着本文对感知质量量表的 5 个题目进行因子分析后, 由表 11 可知, “感知品质”的累计解释变异量达 66.709\% ( > 50\%), 说明此量表具有很高的解释性。

表 10. 感知质量量表 KMO 和 Bartlett's 球形检验

\begin{tabular}{ccc}
\hline KMO 值 & 0.855 & \\
\hline & 近似卡方值 & $1,387.247$ \\
Bartlett's 球形检验 & 自由度 & 10 \\
& $\mathrm{P}$ 值 & 0.000 \\
\hline
\end{tabular}

数据源：作者整理，2019 年 4 月

\subsection{4 感知价值因子分析}

本文通过因子分析对问卷的有效度进行检验, 由表 12 可知, 感知量表 KMO 为 $0.880(0.8<\mathrm{KMO}<0.9)$ ，且 Bartlett's 球形检验卡方值也显著水平，分析结果见下表 4-10 所示。接着本文对感知价值量表的 5 个题目进行因子分析后，由表 13 可知，“感 知价值”的累计解释变异量达 77.140\% ( > 50\%), 说明此量表具有很高的解释性。 
表 11. 感知质量量表因子分析

\begin{tabular}{lc}
\hline \multicolumn{1}{c}{ 题目 } & 因子负荷量 \\
\hline & 1 \\
1.微信小程序操作接口简单流畅 & 0.849 \\
2.微信小程序的支付系统便捷完善 & 0.856 \\
3.使用微信小程序可以使您更便利地获得您所需的服务 & 0.870 \\
4.您在使用微信小程序获得所需服务的过程总体是安全的 & 0.847 \\
5.您使用微信小程序时，没有遇到过软件崩溃或者闪退的情况 & 0.638 \\
\hline 特征值 & 3.335 \\
解释变异量 $(\%)$ & 66.709 \\
累计解释变异量 $(\%)$ & 66.709 \\
\hline
\end{tabular}

数据源：作者整理，2019 年 4 月

表 12. 感知价值量表 KMO 和 Bartlett's 球形检验

\begin{tabular}{ccc}
\hline KMO 值 & & \\
\hline & 近似卡方值 & 2,880 \\
Bartlett's 球形检验 & 自由度 & 10 \\
& $\mathrm{P}$ 值 & 0.000 \\
\hline
\end{tabular}

数据源：作者整理，2019 年 4 月

表 13. 感知价值量表因子分析

\begin{tabular}{|c|c|}
\hline 题目 & 因子负荷量 \\
\hline & 1 \\
\hline 1.微信小程序可以让您在获得相同的服务时更加便利 & 0.875 \\
\hline 2. 微信小程序可以让您花费同样的钱获得更好的服务 & 0.874 \\
\hline 3.微信小程序可以让您在获得相同的服务时更加省时 & 0.919 \\
\hline 4.微信小程序可以让您花更少的时间查找到喜欢的产品及服务 & 0.883 \\
\hline $\begin{array}{l}\text { 5.相比使用其他服务 APP, 你更愿意花费同样的时间和金钱在微信小程 } \\
\text { 序上 }\end{array}$ & 0.838 \\
\hline 特征值 & 3.857 \\
\hline 解释变异量（\%） & 77.140 \\
\hline 累计解释变异量 (\%) & 77.140 \\
\hline
\end{tabular}

数据源：作者整理，2019 年 4 月

\subsection{5 顾客满意因子分析}

本文通过探索性因子分析对问卷的有效度进行检验, 由表 14 可知，顾客满意量 表 $\mathrm{KMO}$ 为 $0.764(0.7<\mathrm{KMO}<0.8)$, 且 Bartlett's 球形检验卡方值也显著水平，分析 结果见下表 14 所示。接着本文对顾客满意量表的 3 个题目进行因子分析后, 由表 15 可知, “顾客满意”的累计解释变异量达 $88.173 \%$ ( > 50\%), 说明此量表具有很高的解 释性。 
表 14. 顾客满意量表 KMO 和 Bartlett's 球形检验

\begin{tabular}{ccc}
\hline KMO 值 & 0.764 & \\
\hline & 近似卡方值 & $1,347.085$ \\
Bartlett's 球形检验 & 自由度 & 3 \\
& $\mathrm{P}$ 值 & 0.000 \\
\hline
\end{tabular}

数据源：作者整理，2019 年 4 月

表 15. 顾客满意量表因子分析

题目因子负荷量

1. 您对微信小程序总体上是满意的

0.944

2.微信小程序的使用体验达到了您的预期

0.944

3.您愿意给微信小程序一个很高的评价

0.929

\section{特征值}

2.645

解释变异量 $(\%)$

88.173

累计解释变异量 $(\%)$

88.173

数据源：作者整理，2019 年 4 月

\subsection{6 顾客忠诚因子分析}

本文通过因子分析对问卷的有效度进行检验, 由表 16 可知, 顾客忠诚量表 $\mathrm{KMO}$ 为 $0.719(0.7<\mathrm{KMO}<0.8)$, 且 Bartlett's 球形检验卡方值也显著水平, 分析结果见 下表 16 所示。接着本文对顾客忠诚量表的 3 个题目进行因子分析后, 由表 17 可知, “顾客忠诚”的累计解释变异量达 $81.299 \%$ ( > $50 \%$ ), 说明此量表具有很高的解释性。 表 16. 顾客忠诚量表 KMO 和 Bartlett's 球形检验

\begin{tabular}{ccc}
\hline KMO 值 & 0.719 & \\
\hline & 近似卡方值 & 955.483 \\
Bartlett's 球形检验 & 自由度 & 3 \\
& $\mathrm{P}$ 值 & 0.000 \\
\hline
\end{tabular}

数据源：作者整理，2019 年 4 月

表 17. 顾客忠诚量表因子分析

\begin{tabular}{lc}
\hline 题目 & 因子负荷量 \\
\hline & 1 \\
1.您会继续使用微信小程序 & 0.858 \\
2.您会向您的亲朋好友推荐微信小程序 & 0.925 \\
3.您愿意向别人宣传微信小程序 & 0.920 \\
\hline 特征值 & 2.439 \\
解释变异量 $(\%)$ & 81.299 \\
累计解释变异量 $(\%)$ & 81.299 \\
\hline
\end{tabular}

数据源：作者整理，2019 年 4 月 


\section{4 相关性分析}

相关性分析主要是研究各变量之间是否有显著的相关性。判断相关性系数数值 范围在-1 和 1 之间, 此系数越接近 1 表示两个变量间有显著的正相关; 接近-1 表示 两个变量之间有显著的负相关; 越接近 0 表示两者缺乏线性相关。本研究采用相关 分析法来研究微信小程序用户所体现的品牌形象、预期质量、感知质量、感知价值、 顾客满意度和顾客忠诚度之间的相关关系。具体分析结果如下表 18 所示。

表 18. 各变量的相关性分析

\begin{tabular}{ccccccccc}
\hline 变数 & 均值 & 标准偏差 & 品牌形象 & 预期质量 & 感知品质 & 感知价值 & 顾客满意 & 顾客忠诚 \\
\hline 品牌形象 & 3.6292 & 0.8613 & 1 & & & & & \\
预期质量 & 3.5159 & 0.8333 & $0.691^{* *}$ & 1 & & & & \\
感知品质 & 3.5952 & 0.7819 & $0.668^{* *}$ & $0.815^{* *}$ & 1 & & & \\
感知价值 & 3.5519 & 0.8083 & $0.672^{* *}$ & $0.816^{* *}$ & $0.837^{* *}$ & 1 & & \\
顾客满意 & 3.5840 & 0.8171 & $0.689^{* *}$ & $0.841^{* *}$ & $0.809^{* *}$ & $0.855^{* *}$ & 1 & \\
顾客忠诚 & 3.5673 & 0.8601 & $0.649^{* *}$ & $0.785^{* *}$ & $0.762^{* *}$ & $0.829^{* *}$ & $0.864^{* *}$ & 1 \\
\hline
\end{tabular}

数据源：作者整理, 2019 年 4 月

*** 在 0.001 水平(双侧)上显著相关; ${ }^{* *}$ 在 0.01 水平(双侧)上显著相关; ${ }^{*}$ 在 0.05 水平(双侧)上显著相关

品牌形象与预期质量呈显著正相关 $(\mathrm{r}=0.691, \mathrm{p}<0.01)$, 品牌形象与感知质量呈 现正相关 $(r=0.668, \mathrm{p}<0.01)$, 品牌形象与感知价值呈现正相关 $(r=0.672, \mathrm{p}<0.01)$, 品牌形象与顾客满意呈现正相关 $(r=0.689, \mathrm{p}<0.01)$, 品牌形象与顾客忠诚呈现正相 关 $(\mathrm{r}=0.649, \mathrm{p}<0.01)$ ，预期质量与感知质量呈现正相关 $(\mathrm{r}=0.815, \mathrm{p}<0.01)$ ，预期质 量与感知价值呈现正相关 $(\mathrm{r}=0.816, \mathrm{p}<0.01)$ ，预期质量与顾客满意呈现正相关 $(\mathrm{r}=0.841, \mathrm{p}<0.01)$ ，预期质量与顾客忠诚呈现正相关 $(\mathrm{r}=0.785, \mathrm{p}<0.01)$ ，感知质量 与感知价值呈现正相关 $(r=0.837, p<0.01)$, 感知质量与顾客满意呈现正相关 $(r=0.809$, $\mathrm{p}<0.01)$, 感知质量与顾客忠诚呈现正相关 $(r=0.762, \mathrm{p}<0.01)$, 感知价值与顾客满 意呈现正相关 $(r=0.855, \mathrm{p}<0.01)$, 感知价值与顾客忠诚呈现正相关 $(r=0.829, \mathrm{p}<0.01)$, 顾客满意与顾客忠诚呈现正相关 $(r=864, \mathrm{p}<0.01)$ 。

\section{5 多元回归分析}

\subsection{1 品牌形象对感知质量的回归分析}

由表 19 可以看出, 通过 $\mathrm{F}$ 检验, 模型 2 的 $\mathrm{F}$ 统计值达显著水平, 说明模型 2 的 总体回归效果是好的。模型 2 中的标准化回归系数为 $0.591, \mathrm{t}$ 值为 19.867 , 有达显 著水平。由此可知, 假设 $\mathrm{H} 1$ 成立。

\subsection{2 品牌形象对预期质量的回归分析}

由表 20 可以看出, 通过 $\mathrm{F}$ 检验, 模型 2 的 $\mathrm{F}$ 统计值达显著水平, 说明模型 2 的 总体回归效果是好的。模型 2 中的标准化回归系数为 $0.655, \mathrm{t}$ 值为 21.286 , 有达显 著水平。由此可知, 假设 $\mathrm{H} 2$ 成立。 
表 19. 品牌形象对感知质量的回归分析

\begin{tabular}{|c|c|c|c|c|c|c|}
\hline \multirow{3}{*}{ 因变数 } & \multicolumn{6}{|c|}{ 感知质量 } \\
\hline & \multicolumn{3}{|c|}{ 模型 1} & \multicolumn{3}{|c|}{ 模型 2} \\
\hline & B & $\mathrm{t}$ & Sig. & B & $\mathrm{t}$ & Sig. \\
\hline \multicolumn{7}{|l|}{ 控制变量 } \\
\hline 性别 & -0.550 & -0.779 & 0.437 & -0.410 & -0.770 & 0.442 \\
\hline 年龄 & 0.129 & 3.364 & $0.010^{*}$ & 0.066 & 2.278 & $0.023^{*}$ \\
\hline 职业 & -0.019 & -1.004 & 0.316 & -0.011 & -0.793 & 0.428 \\
\hline 受教育程度 & -0.156 & -3.147 & $0.002^{* *}$ & -0.040 & -1.040 & 0.299 \\
\hline 个人月收入 & -0.029 & -0.941 & 0.347 & -0.016 & -0.702 & 0.483 \\
\hline \multicolumn{7}{|l|}{ 自变量 } \\
\hline 品牌形象 & & & & 0.591 & 19.867 & $0.000^{* * *}$ \\
\hline $\mathrm{R}^{2}$ & & 0.050 & & & 0.454 & \\
\hline 调整后 $\mathrm{R}^{2}$ & & 0.041 & & & 0.448 & \\
\hline R² 变更 & & 0.050 & & & 0.404 & \\
\hline $\mathrm{F}$ 值 & & 5.566 & & & 0.000 & \\
\hline
\end{tabular}

数据源：作者整理，2019 年 4 月

*** 在 0.001 水平(双侧)上显著相关; ${ }^{* *}$ 在 0.01 水平(双侧)上显著相关; ${ }^{*}$ 在 0.05 水平(双侧)上显著相关 表 20. 品牌形象对预期质量的回归分析

\begin{tabular}{|c|c|c|c|c|c|c|}
\hline \multirow{3}{*}{ 因变数 } & \multicolumn{6}{|c|}{ 预期质量 } \\
\hline & \multicolumn{3}{|c|}{ 模型 1} & \multicolumn{3}{|c|}{ 模型 2} \\
\hline & B & $\mathrm{t}$ & Sig. & B & $\mathrm{t}$ & Sig. \\
\hline \multicolumn{7}{|l|}{ 控制变量 } \\
\hline 性别 & 0.040 & 0.538 & 0.591 & 0.056 & 1.006 & 0.315 \\
\hline 年龄 & 0.141 & 3.464 & $0.001^{* *}$ & 0.072 & 2.397 & $0.017^{*}$ \\
\hline 职业 & -0.025 & -1.273 & 0.203 & -0.017 & -1.162 & 0.246 \\
\hline 受教育程度 & -0.165 & -3.113 & $0.002^{* *}$ & -0.036 & -0.903 & 0.367 \\
\hline 个人月收入 & -0.024 & -0.741 & 0.459 & -0.010 & -0.430 & 0.667 \\
\hline \multicolumn{7}{|l|}{ 自变量 } \\
\hline 品牌形象 & & & & 0.655 & 21.286 & $0.000^{* * *}$ \\
\hline $\mathrm{R}^{2}$ & & 0.050 & & & 0.486 & \\
\hline 调整后 $\mathrm{R}^{2}$ & & 0.041 & & & 0.481 & \\
\hline R $^{2}$ 变更 & & 0.050 & & & 0.437 & \\
\hline $\mathrm{F}$ 值 & & 5.608 & & & 0.000 & \\
\hline
\end{tabular}

数据源：作者整理, 2019 年 4 月

${ }^{* * *}$ 在 0.001 水平 $\left(\right.$ 双侧)上显著相关; ${ }^{* *}$ 在 0.01 水平(双侧)上显著相关 ; ${ }^{*}$ 在 0.05 水平(双侧)上显著相关

\subsection{3 品牌形象对感知价值的回归分析}

由表 21 可以看出, 通过 $\mathrm{F}$ 检验, 模型 2 的 $\mathrm{F}$ 统计值达显著水平, 说明模型 2 的 总体回归效果是好的。模型 2 中的标准化回归系数为 $0.605, \mathrm{t}$ 值为 19.973 , 有达显 著水平。由此可知, 假设 $\mathrm{H} 3$ 成立。 
表 21. 品牌形象对感知价值的回归分析

\begin{tabular}{|c|c|c|c|c|c|c|}
\hline \multirow{3}{*}{ 因变数 } & \multicolumn{6}{|c|}{ 感知价值 } \\
\hline & \multicolumn{3}{|c|}{ 模型 1} & \multicolumn{3}{|c|}{ 模型 2} \\
\hline & B & $\mathrm{t}$ & Sig. & B & $\mathrm{t}$ & Sig. \\
\hline \multicolumn{7}{|l|}{ 控制变量 } \\
\hline 性别 & 0.030 & 0.414 & 0.679 & 0.044 & 0.804 & 0.421 \\
\hline 年龄 & 0.152 & 3.887 & $0.000^{* * *}$ & 0.088 & 2.964 & $0.003^{* *}$ \\
\hline 职业 & -0.029 & -1.506 & 0.133 & -0.021 & -1.456 & 0.146 \\
\hline 受教育程度 & -0.211 & -4.168 & $0.000^{* * *}$ & -0.092 & -2.365 & $0.018^{*}$ \\
\hline 个人月收入 & -0.013 & -0.415 & 0.678 & 0.000 & -0.007 & 0.995 \\
\hline \multicolumn{7}{|l|}{ 自变量 } \\
\hline 品牌形象 & & & & 0.605 & 19.973 & $0.000^{* * *}$ \\
\hline $\mathrm{R}^{2}$ & & 0.073 & & & 0.470 & \\
\hline 调整后 $\mathrm{R}^{2}$ & & 0.065 & & & 0.464 & \\
\hline R² 变更 & & 0.073 & & & 0.397 & \\
\hline $\mathrm{F}$ 值 & & 8.451 & & & 0.000 & \\
\hline
\end{tabular}

数据源：作者整理，2019 年 4 月

*** 在 0.001 水平 $($ 双侧 $)$ 上显著相关; ${ }^{* *}$ 在 0.01 水平(双侧)上显著相关; ${ }^{*}$ 在 0.05 水平(双侧)上显著相关

\subsection{4 品牌形象对顾客满意的回归分析}

由表 22 可以看出, 通过 $\mathrm{F}$ 检验, 模型 2 的 $\mathrm{F}$ 统计值达显著水平, 说明模型 2 的 总体回归效果是好的。模型 2 中的标准化回归系数为 $0.633, \mathrm{t}$ 值为 21.083 , 有达显 著水平。由此可知, 假设 $\mathrm{H} 4$ 成立。

表 22. 品牌形象对顾客满意的回归分析

\begin{tabular}{|c|c|c|c|c|c|c|}
\hline \multirow{3}{*}{ 因变数 } & \multicolumn{6}{|c|}{ 顾客满意 } \\
\hline & \multicolumn{3}{|c|}{ 模型 1} & \multicolumn{3}{|c|}{ 模型 2} \\
\hline & B & $\mathrm{t}$ & Sig. & B & $\mathrm{t}$ & Sig. \\
\hline \multicolumn{7}{|l|}{ 控制变量 } \\
\hline 性别 & 0.078 & 1.061 & 0.289 & 0.092 & 1.707 & 0.088 \\
\hline 年龄 & 0.126 & 3.194 & $0.001^{* *}$ & 0.060 & 2.035 & $0.042^{*}$ \\
\hline 职业 & -0.032 & -1.669 & 0.096 & -0.024 & -1.695 & 0.091 \\
\hline 受教育程度 & -0.223 & -4.340 & $0.000^{* * *}$ & -0.098 & -2.556 & $0.011^{*}$ \\
\hline 个人月收入 & -0.006 & -0.172 & 0.863 & 0.008 & 0.338 & 0.736 \\
\hline \multicolumn{7}{|l|}{ 自变量 } \\
\hline 品牌形象 & & & & 0.633 & 21.083 & $0.000^{* * *}$ \\
\hline $\mathrm{R}^{2}$ & & 0.066 & & & 0.491 & \\
\hline 调整后 $\mathrm{R}^{2}$ & & 0.057 & & & 0.485 & \\
\hline $\mathrm{R}^{2}$ 变更 & & 0.066 & & & 0.425 & \\
\hline $\mathrm{F}$ 值 & & 7.546 & & & 0.000 & \\
\hline
\end{tabular}

数据源：作者整理，2019 年 4 月

\subsection{5 预期质量对感知价值的回归分析}

由表 23 可以看出, 通过 $\mathrm{F}$ 检验, 模型 2 的 $\mathrm{F}$ 统计值达显著水平, 说明模型 2 的 总体回归效果是好的。模型 2 中的标准化回归系数为 $0.772, \mathrm{t}$ 值为 31.413 , 有达显 著水平。由此可知, 假设 $\mathrm{H} 5$ 成立。 
表 23. 预期质量对感知价值的回归分析

\begin{tabular}{|c|c|c|c|c|c|c|}
\hline \multirow{3}{*}{ 因变数 } & \multicolumn{6}{|c|}{ 感知价值 } \\
\hline & \multicolumn{3}{|c|}{ 模型 1} & \multicolumn{3}{|c|}{ 模型 2} \\
\hline & B & $\mathrm{t}$ & Sig. & B & $\mathrm{t}$ & Sig. \\
\hline \multicolumn{7}{|l|}{ 控制变量 } \\
\hline 性别 & 0.030 & 0.414 & 0.679 & -0.001 & -0.033 & 0.974 \\
\hline 年龄 & 0.152 & 3.887 & $0.000^{* * *}$ & 0.043 & 1.829 & 0.068 \\
\hline 职业 & -0.029 & -1.506 & 0.133 & -0.009 & -0.809 & 0.419 \\
\hline 受教育程度 & -0.211 & -4.168 & $0.000^{* * *}$ & -0.084 & -2.773 & $0.006^{* *}$ \\
\hline 个人月收入 & -0.013 & -0.415 & 0.678 & 0.006 & 0.308 & 0.758 \\
\hline \multicolumn{7}{|l|}{ 自变量 } \\
\hline 预期质量 & & & & 0.772 & 31.413 & $0.000^{* * *}$ \\
\hline $\mathrm{R}^{2}$ & & 0.073 & & & 0.675 & \\
\hline 调整后 $\mathrm{R}^{2}$ & & 0.065 & & & 0.671 & \\
\hline R² 变更 & & 0.073 & & & 0.602 & \\
\hline $\mathrm{F}$ 值 & & 8.451 & & & 0.000 & \\
\hline
\end{tabular}

数据源：作者整理，2019 年 4 月

${ }^{* * *}$ 在 0.001 水平 $($ 双侧 $)$ 上显著相关; ${ }^{* *}$ 在 0.01 水平 $\left(\right.$ 双侧)上显著相关; ${ }^{*}$ 在 0.05 水平(双侧)上显著相关

\subsection{6 预期质量对感知质量的回归分析}

由表 24 可以看出, 通过 $\mathrm{F}$ 检验, 模型 2 的 $\mathrm{F}$ 统计值达显著水平, 说明模型 2 的 总体回归效果是好的。模型 2 中的标准化回归系数为 $0.757, \mathrm{t}$ 值为 31.560 , 有达显 著水平。由此可知, 假设 $\mathrm{H} 6$ 成立。

表 24. 预期质量对感知质量的回归分析

\begin{tabular}{|c|c|c|c|c|c|c|}
\hline \multirow{3}{*}{ 因变数 } & \multicolumn{6}{|c|}{ 感知质量 } \\
\hline & \multicolumn{3}{|c|}{ 模型 1} & \multicolumn{3}{|c|}{ 模型 2} \\
\hline & B & $\mathrm{t}$ & Sig. & B & $\mathrm{t}$ & Sig. \\
\hline \multicolumn{7}{|l|}{ 控制变量 } \\
\hline 性别 & -0.055 & -0.079 & 0.437 & -0.086 & -2.052 & $0.041^{*}$ \\
\hline 年龄 & 0.129 & 3.364 & $0.001^{* *}$ & 0.022 & 0.952 & 0.342 \\
\hline 职业 & -0.019 & -1.004 & 0.316 & 0.000 & 0.040 & 0.968 \\
\hline 受教育程度 & -0.156 & -3.147 & $0.002^{* *}$ & -0.032 & -1.063 & 0.288 \\
\hline 个人月收入 & -0.029 & -0.941 & 0.347 & -0.011 & -0.579 & 0.563 \\
\hline \multicolumn{7}{|l|}{ 自变量 } \\
\hline 预期质量 & & & & 0.757 & 31.560 & $0.000^{* * *}$ \\
\hline $\mathrm{R}^{2}$ & & 0.050 & & & 0.669 & \\
\hline 调整后 $\mathrm{R}^{2}$ & & 0.041 & & & 0.665 & \\
\hline $\mathrm{R}^{2}$ 变更 & & 0.050 & & & 0.619 & \\
\hline $\mathrm{F}$ 值 & & 5.566 & & & 0.000 & \\
\hline
\end{tabular}

数据源：作者整理， 2019 年 4 月

\subsection{7 预期质量对顾客满意的回归分析}

由表 25 可以看出, 通过 $\mathrm{F}$ 检验, 模型 2 的 $\mathrm{F}$ 统计值达显著水平, 说明模型 2 的 总体回归效果是好的。模型 2 中的标准化回归系数为 $0.810, \mathrm{t}$ 值为 34.754 , 有达显 著水平。由此可知, 假设 $\mathrm{H} 7$ 成立。 
表 25. 预期质量对顾客满意的回归分析

\begin{tabular}{|c|c|c|c|c|c|c|}
\hline \multirow{3}{*}{ 因变数 } & \multicolumn{6}{|c|}{ 顾客满意 } \\
\hline & \multicolumn{3}{|c|}{ 模型 1} & \multicolumn{3}{|c|}{ 模型 2} \\
\hline & B & $\mathrm{t}$ & Sig. & B & $\mathrm{t}$ & Sig. \\
\hline \multicolumn{7}{|l|}{ 控制变量 } \\
\hline 性别 & 0.078 & 1.061 & 0.289 & 0.045 & 1.106 & 0.269 \\
\hline 年龄 & 0.126 & 3.194 & $0.001^{* *}$ & 0.012 & 0.551 & 0.582 \\
\hline 职业 & -0.032 & -1.669 & 0.096 & -0.012 & -1.097 & 0.273 \\
\hline 受教育程度 & -0.223 & -4.340 & $0.000^{* * *}$ & -0.090 & -3.125 & $0.002^{* *}$ \\
\hline 个人月收入 & -0.006 & -0.172 & 0.863 & 0.014 & 0.803 & 0.422 \\
\hline \multicolumn{7}{|l|}{ 自变量 } \\
\hline 预期质量 & & & & 0.810 & 34.754 & $0.000^{* * *}$ \\
\hline $\mathrm{R}^{2}$ & & 0.066 & & & 0.714 & \\
\hline 调整后 $\mathrm{R}^{2}$ & & 0.057 & & & 0.711 & \\
\hline R² 变更 & & 0.066 & & & 0.648 & \\
\hline $\mathrm{F}$ 值 & & 7.546 & & & 0.000 & \\
\hline
\end{tabular}

数据源：作者整理，2019 年 4 月

*** 在 0.001 水平 $\left(\right.$ 双侧)上显著相关; ${ }^{* *}$ 在 0.01 水平 $\left(\right.$ 双侧)上显著相关; ${ }^{*}$ 在 0.05 水平(双侧)上显著相关

\subsection{8 感知质量对感知价值的回归分析}

由表 26 可以看出, 通过 $\mathrm{F}$ 检验, 模型 2 的 $\mathrm{F}$ 统计值达显著水平, 说明模型 2 的 总体回归结果是好的。模型 2 中的标准化回归系数为 $0.847, \mathrm{t}$ 值为 34.287 , 有达显 著水平。由此可知, 假设 $\mathrm{H} 8$ 成立。

表 26. 感知质量对感知价值的回归分析

\begin{tabular}{|c|c|c|c|c|c|c|}
\hline \multirow{3}{*}{ 因变数 } & \multicolumn{6}{|c|}{ 感知价值 } \\
\hline & \multicolumn{3}{|c|}{ 模型 1} & \multicolumn{3}{|c|}{ 模型 2} \\
\hline & B & $\mathrm{t}$ & Sig. & B & $\mathrm{t}$ & Sig. \\
\hline \multicolumn{7}{|l|}{ 控制变量 } \\
\hline 性别 & 0.030 & 0.414 & 0.679 & 0.076 & 1.895 & 0.059 \\
\hline 年龄 & 0.152 & 3.887 & $0.000^{* * *}$ & 0.043 & 1.941 & 0.053 \\
\hline 职业 & -0.029 & -1.506 & 0.133 & -0.013 & -1.203 & 0.229 \\
\hline 受教育程度 & -0.211 & -4.168 & $0.000^{* * * *}$ & -0.079 & -2.760 & $0.006^{* * *}$ \\
\hline 个人月收入 & 0.013 & -0.415 & 0.678 & 0.012 & 0.654 & 0.514 \\
\hline \multicolumn{7}{|l|}{ 自变量 } \\
\hline 感知质量 & & & & 0.847 & 34.287 & $0.000^{* * *}$ \\
\hline $\mathrm{R}^{2}$ & & 0.073 & & & 0.711 & \\
\hline 调整后 $\mathrm{R}^{2}$ & & 0.065 & & & 0.708 & \\
\hline $\mathrm{R}^{2}$ 变更 & & 0.073 & & & 0.638 & \\
\hline $\mathrm{F}$ 值 & & 8.451 & & & 0.000 & \\
\hline
\end{tabular}

数据源：作者整理， 2019 年 4 月

\subsection{9 感知质量对顾客满意的回归分析}

由表 27 可以看出, 通过 $\mathrm{F}$ 检验, 模型 2 的 $\mathrm{F}$ 统计值达显著水平, 说明模型 2 的 总体回归效果是好的。模型 2 中的标准化回归系数为 $0.831, \mathrm{t}$ 值为 30.973 , 有达显 著水平。由此可知, 假设 $\mathrm{H} 9$ 成立。 
表 27. 感知质量对顾客满意的回归分析

\begin{tabular}{|c|c|c|c|c|c|c|}
\hline \multirow{3}{*}{ 因变数 } & \multicolumn{6}{|c|}{ 顾客满意 } \\
\hline & \multicolumn{3}{|c|}{ 模型 1} & \multicolumn{3}{|c|}{ 模型 2} \\
\hline & B & $\mathrm{t}$ & Sig. & B & $\mathrm{t}$ & Sig. \\
\hline \multicolumn{7}{|l|}{ 控制变量 } \\
\hline 性别 & 0.078 & 1.061 & 0.289 & 0.123 & 2.816 & $0.005^{* *}$ \\
\hline 年龄 & 0.126 & 3.194 & $0.001^{* *}$ & 0.020 & 0.821 & 0.412 \\
\hline 职业 & -0.032 & -1.669 & 0.096 & -0.017 & -1.443 & 0.150 \\
\hline 受教育程度 & -0.223 & -4.340 & $0.000^{* * *}$ & -0.094 & -3.009 & $0.003 * *$ \\
\hline 个人月收入 & -0.006 & -0.172 & 0.863 & 0.019 & 0.972 & 0.331 \\
\hline \multicolumn{7}{|l|}{ 自变量 } \\
\hline 感知质量 & & & & 0.831 & 30.973 & $0.000^{* * * *}$ \\
\hline $\mathrm{R}^{2}$ & & 0.066 & & & 0.666 & \\
\hline 调整后 $\mathrm{R}^{2}$ & & 0.057 & & & 0.663 & \\
\hline $\mathrm{R}^{2}$ 变更 & & 0.066 & & & 0.600 & \\
\hline $\mathrm{F}$ 值 & & 7.546 & & & 0.000 & \\
\hline
\end{tabular}

数据源：作者整理，2019 年 4 月

***在 0.001 水平(双侧)上显著相关; ${ }^{* *}$ 在 0.01 水平(双侧)上显著相关 ; ${ }^{*}$ 在 0.05 水平(双侧)上显著相关

\subsection{9 感知价值对顾客满意的回归分析}

由表 28 可以看出, 通过 $\mathrm{F}$ 检验, 模型 2 的 $\mathrm{F}$ 统计值达显著水平, 说明模型 2 的 总体回归效果是好的。模型 2 中的标准化回归系数为 $0.858, \mathrm{t}$ 值为 36.505 , 有达显 著水平。由此可知, 假设 $\mathrm{H} 10$ 成立。

表 28. 感知价值对顾客满意的回归分析

\begin{tabular}{|c|c|c|c|c|c|c|}
\hline \multirow{3}{*}{ 因变数 } & \multicolumn{6}{|c|}{ 顾客满意 } \\
\hline & \multicolumn{3}{|c|}{ 模型 1} & \multicolumn{3}{|c|}{ 模型 2} \\
\hline & B & $\mathrm{t}$ & Sig. & B & $\mathrm{t}$ & Sig. \\
\hline \multicolumn{7}{|l|}{ 控制变量 } \\
\hline 性别 & 0.078 & 1.061 & 0.289 & 0.052 & 1.329 & 0.184 \\
\hline 年龄 & 0.126 & 3.194 & $0.001^{* *}$ & -0.004 & -0.169 & 0.866 \\
\hline 职业 & -0.032 & -1.669 & 0.096 & -0.008 & -0.739 & 0.460 \\
\hline 受教育程度 & -0.223 & -4.340 & $0.000^{* * *}$ & -0.042 & -1.504 & 0.133 \\
\hline 个人月收入 & -0.006 & 0.172 & 0.863 & 0.006 & 0.333 & 0.739 \\
\hline \multicolumn{7}{|l|}{ 自变量 } \\
\hline 感知价值 & & & & 0.858 & 36.505 & $0.000^{* * *}$ \\
\hline $\mathrm{R}^{2}$ & & 0.066 & & & 0.733 & \\
\hline 调整后 $\mathrm{R}^{2}$ & & 0.057 & & & 0.730 & \\
\hline $\mathrm{R}^{2}$ 变更 & & 0.066 & & & 0.667 & \\
\hline $\mathrm{F}$ 值 & & 7.546 & & & 0.000 & \\
\hline
\end{tabular}

数据源：作者整理，2019 年 4 月

\subsubsection{1 顾客满意对顾客忠诚的回归分析}

由表 29 可以看出, 通过 $\mathrm{F}$ 检验, 模型 2 的 $\mathrm{F}$ 统计值达显著水平, 说明模型 2 的 总体回归效果是好的。模型 2 中的标准化回归系数为 $0.904, \mathrm{t}$ 值为 38.161 , 有达显 著水平。由此可知, 假设 H11 成立。 
表 29. 顾客满意对顾客忠诚的回归分析

\begin{tabular}{|c|c|c|c|c|c|c|}
\hline \multirow{3}{*}{ 因变数 } & \multicolumn{6}{|c|}{ 顾客忠诚 } \\
\hline & \multicolumn{3}{|c|}{ 模型 1} & \multicolumn{3}{|c|}{ 模型 2} \\
\hline & B & $\mathrm{t}$ & Sig. & B & $\mathrm{t}$ & Sig. \\
\hline \multicolumn{7}{|l|}{ 控制变量 } \\
\hline 性别 & 0.115 & 1.497 & 0.135 & 0.045 & 1.135 & 0.257 \\
\hline 年龄 & 0.142 & 3.384 & $0.001^{* *}$ & 0.027 & 1.245 & 0.214 \\
\hline 职业 & -0.038 & -1.854 & 0.064 & -0.009 & -0.820 & 0.413 \\
\hline 受教育程度 & -0.201 & -3.692 & $0.000^{* * *}$ & 0.001 & 0.041 & 0.967 \\
\hline 个人月收入 & -0.011 & -0.332 & 0.740 & -0.006 & -0.357 & 0.721 \\
\hline \multicolumn{7}{|l|}{ 自变量 } \\
\hline 顾客满意 & & & & 0.904 & 38.161 & $0.000^{* * *}$ \\
\hline $\mathrm{R}^{2}$ & & 0.059 & & & 0.748 & \\
\hline 调整后 $\mathrm{R}^{2}$ & & 0.051 & & & 0.745 & \\
\hline R² 变更 & & 0.059 & & & 0.689 & \\
\hline $\mathrm{F}$ 值 & & 6.745 & & & 0.000 & \\
\hline
\end{tabular}

数据源：作者整理，2019 年 4 月

*** 在 0.001 水平(双侧)上显著相关; ${ }^{* *}$ 在 0.01 水平(双侧)上显著相关; ${ }^{*}$ 在 0.05 水平(双侧)上显著相关

\section{5. 路径分析}

\section{1 模型修正}

本研究在前文中已经以 CCSI 模型作为基础, 提出对微信小程序满意度影响因素 的研究假设且已经证明, 基于 CCSI 模型所确定的六个维度信度均大于 0.8 , 问卷整 体信度大于 0.9 , 问卷信度良好。且各项维度之间相关性也非常不错, 所以在此基础 上, 对 CCSI 模型进行修正。具体实施方案为: 将感知质量、预期质量、品牌形象三 个自变量合三为一, 将新得维度命名为品牌质量, 作为自变量, 保持感知价值、顾客 满意及顾客忠诚三个维度不变, 顾客忠诚作为最终变量, 对其满意度影响因素的路径 进行进一步的分析, 得到新得模型, 详情请见图 2。

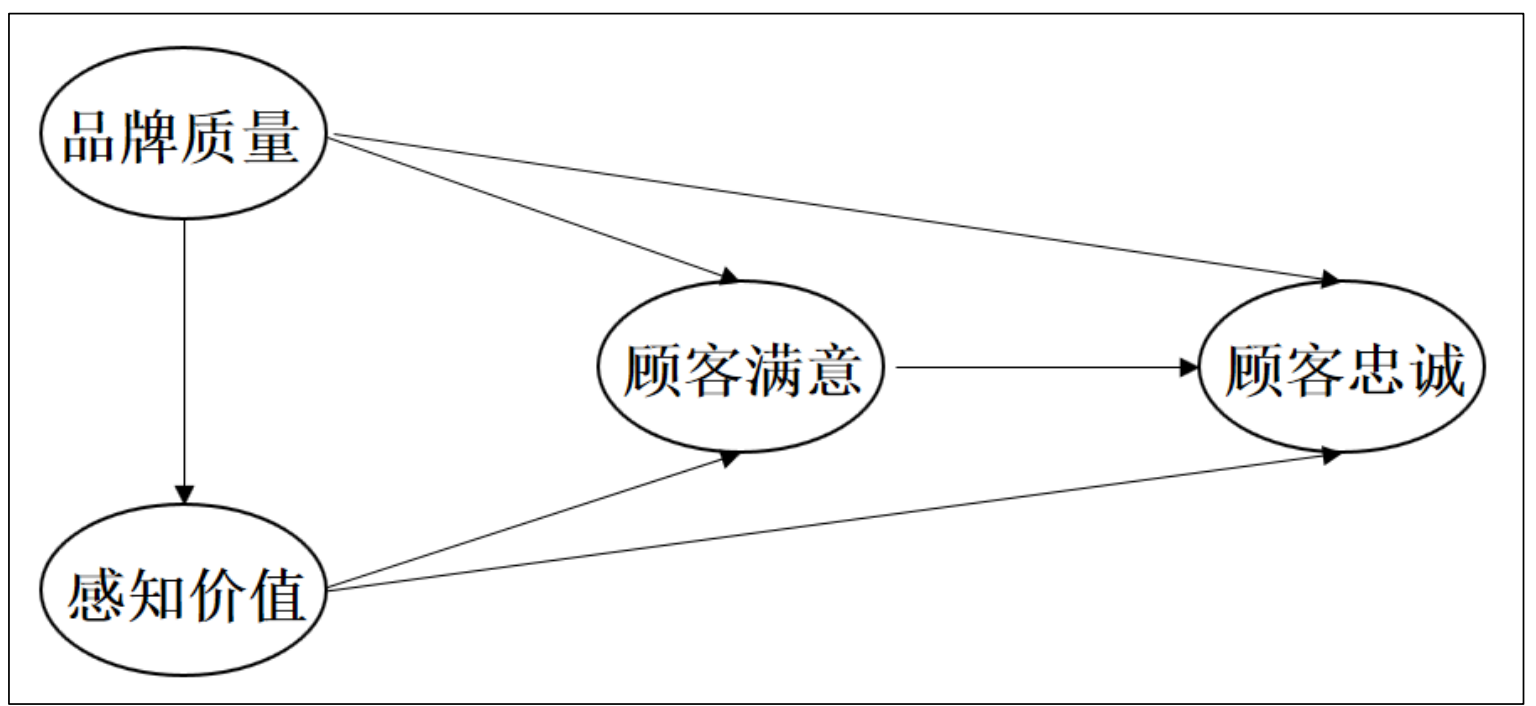

数据源：作者整理， 2019 年 4 月

图 2. 微信小程序路径分析模型 


\section{2 提出假设}

根据本文针对路径研究所设计的模型, 自变量是品牌形象, 中介变量是感知价值 和顾客满意, 因变数是顾客忠诚。本次路径研究主要是研究品牌质量、感知价值、顾 客满意和顾客忠诚之间影响微信小程序满意度的路径研究, 因此, 本次路径研究建议 假设如下：
$\mathrm{H}_{\mathrm{I}}$ ：品牌质量对顾客忠诚度有显著影响
$\mathrm{H}_{\mathrm{II}}$ ：品牌质量通过顾客满意对顾客忠诚有显著影响
$\mathrm{H}_{\mathrm{III}}$ ：品牌质量通过感知价值和顾客满意对顾客忠诚有显著影响
$\mathrm{H}_{\mathrm{IV}}$ ：品牌质量通过感知价值对顾客忠诚有显著影响
$\mathrm{H}_{\mathrm{V}}$ ：感知价值通过顾客满意对顾客忠诚有显著影响
$\mathrm{H}_{\mathrm{VI}}$ ：感知价值对顾客忠诚有显著影响
$\mathrm{H}_{\mathrm{VII}}$ ：顾客满意对顾客忠诚有显著影响

\section{3 资料分析}

因为前文已经做过描述性统计、信度效度、相关性、多元回归分析等分析, 在此 处就不再重复罗列, 直接进入路径分析最直接的验证假设分析: 互回归分析。在互回 归分析中, 因为是路径分析, 所以在模型基础上将互回归分为三次进行, 以验证假设, 每次互回归分析自变量与因变量均会改变。此互回归中用到残差系数公式如下：

$$
\text { 残差系数 }=\sqrt{1-\mathrm{R}^{2}}
$$

\subsection{1 自变量为品牌质量、感知价值、顾客满意的回归分析}

确定自变量为品牌质量、感知价值、顾客满意, 因变量为顾客忠诚, 对此进行互 回归分析。由表 30 可以得, 三个自变量品牌质量、感知价值、顾客满意对因变量顾 客忠诚均有显著影响，整体互回归所得残差系数为 0.47 。在模型中，品牌质量标准化 回归系数为 $0.144, \mathrm{t}$ 值为 2.722 , 有达显著水平; 感知价值标准化回归系数为 0.297 , $\mathrm{t}$ 值为 6.320 ; 顾客满意标准化回归系数为 $0.544, \mathrm{t}$ 值为 11.483 , 有达显著水平。其 中, 品牌质量 B 值最低, 为 0.144 , 顾客满意最高, 为 0.544 , 感知价值良好, 为 0.297 。 三个自变量对应变量的显著性都较高, 均小于 0.01 , 最低的品牌质量为 0.007 , 可以 标两颗星, 而另外两个自变量均为 0 , 均可标三颗星。

\subsection{2 自变量为品牌质量、感知价值的回归分析}

确定自变量为品牌质量、感知价值, 因变量为顾客满意, 对此进行互回归分析。 由表 31 可以得, 两个自变量品牌质量、感知价值对因变量顾客满意均有显著影响, 整体互回归所得残差系数为 0.450 。在模型中, 品牌质量标准化回归系数为 $0.552, \mathrm{t}$ 值为 13.160 , 有达显著水平; 感知价值标准化回归系数为 $0.426, \mathrm{t}$ 值为 10.993 。其 中, 品牌质量 B 值为 0.552 , 感知价值为 0.426 , 两个自变量对应变量的显著性都较 高, 均小于 0.001 , 均可标三颗星。 
表 30. 因变量为顾客忠诚的互回归模型分析

\begin{tabular}{cccc}
\hline 因变数 & \multicolumn{2}{c}{ 模型 } \\
\cline { 2 - 4 } 顾客忠诚 & $\mathrm{B}$ & $\mathrm{t}$ & $\mathrm{S}$ \\
\hline 自变量 & & & \\
品牌质量 & 0.144 & 2.722 & $0.007^{* * *}$ \\
感知价值 & 0.297 & 6.320 & $0.000^{* * *}$ \\
顾客满意 & 0.544 & 11.483 & $0.000^{* * *}$ \\
\hline $\mathrm{R}^{2}$ & & 0.779 & \\
调整后 $\mathrm{R}^{2}$ & & 0.778 & \\
$\mathrm{R}^{2}$ 变更 & & 0.779 & \\
$\mathrm{~F}$ 值 & & 631.337 & \\
\hline 残差系数 & & 0.470 & \\
\hline
\end{tabular}

数据源：作者整理, 2019 年 4 月

${ }^{* * *}$ 在 0.001 水平(双侧)上显著相关; ${ }^{* *}$ 在 0.01 水平(双侧)上显著相关; ${ }^{*}$ 在 0.05 水平(双侧)上显著相关

表 31. 因变量为顾客满意的互回归模型分析

\begin{tabular}{cccc}
\hline 因变数 & \multicolumn{2}{c}{ 模型 } \\
\cline { 2 - 4 } 顾客满意 & $\mathrm{B}$ & $\mathrm{t}$ & $\mathrm{S}$ \\
\hline 自变量 & & & \\
品牌质量 & 0.552 & 13.160 & $0.000^{* * *}$ \\
感知价值 & 0.426 & 10.993 & $0.000^{* * *}$ \\
\hline $\mathrm{R}^{2}$ & & 0.797 & \\
调整后 $\mathrm{R}^{2}$ & & 0.796 & \\
$\mathrm{R}^{2}$ 变更 & 0.797 & \\
$\mathrm{~F}$ 值 & $1,052.456$ & \\
\hline 残差系数 & & 0.450 & \\
\hline
\end{tabular}

数据源：作者整理，2019 年 4 月

${ }^{* * *}$ 在 0.001 水平 $($ 双侧 $)$ 上显著相关; ${ }^{* *}$ 在 0.01 水平(双侧)上显著相关; ${ }^{*}$ 在 0.05 水平(双侧)上显著相关

\subsection{3 自变量为品牌质量的回归分析}

确定自变量为品牌质量, 因变量为感知价值, 对此进行互回归分析。由表 32 可 以得, 自变量品牌质量对因变量感知价值有显著影响, 整体互回归所得残差系数为 0.508 。在模型中, 品牌质量标准化回归系数为 $0.934, \mathrm{t}$ 值为 39.327 , 有达显著水平。 其中, 品牌质量 B 值为 0.934 , 自变量对应变量的显著性都较高, 小于 0.001 , 可标 三颗星。 
表 32. 因变量为感知价值的互回归模型分析

\begin{tabular}{cccc}
\hline 因变数 & \multicolumn{2}{c}{ 模型 } \\
\cline { 2 - 4 } 感知价值 & $\mathrm{B}$ & $\mathrm{t}$ & $\mathrm{Sig}$. \\
\hline 自变量 & & & \\
品牌质量 & 0.934 & 39.327 & \\
\hline $\mathrm{R}^{2}$ & 0.742 & \\
调整后 $\mathrm{R}^{2}$ & 0.741 & \\
$\mathrm{R}^{2}$ 变更 & 0.742 & \\
$\mathrm{~F}$ 值 & $1,546.631$ & \\
\hline 残差系数 & 0.508 & \\
\hline
\end{tabular}

数据源：作者整理, 2019 年 4 月

${ }^{* * *}$ 在 0.001 水平 (双侧)上显著相关; ${ }^{* *}$ 在 0.01 水平(双侧)上显著相关; ${ }^{*}$ 在 0.05 水平(双侧)上显著相关

\section{6. 研究结果综述与展望}

\section{1 研究结果综述}

\subsubsection{CCSI 研究结果综述}

本文以微信小程序作为研究对象, 对问卷调查所收集到的数据进行整理和分析, 验证微信小程序的顾客满意指数模型(CCSI)，假设验证结果整理如表 33 所示。

表 33. CCSI 研究假设验证结果表

\begin{tabular}{ccc}
\hline 序号 & & 研究假设 \\
\hline H1 & 品牌形象对感知质量呈现显著影响果 \\
H2 & 品牌形象对预期质量呈现显著影响 & 成立 \\
H3 & 品牌形象对感知价值呈现显著影响 & 成立 \\
H4 & 品牌形象对顾客满意呈现显著影响 & 成立 \\
H5 & 预期质量对感知价值呈现显著影响 & 成立 \\
H6 & 预期质量对感知质量呈现显著影响 & 成立 \\
H7 & 预期质量对顾客满意呈现显著影响 & 成立 \\
H8 & 感知质量对感知价值呈现显著影响 & 成立 \\
H9 & 感知质量对顾客满意呈现显著影响 & 成立 \\
H10 & 感知价值对顾客满意呈现显著影响 & 成立 \\
H11 & 顾客满意对顾客忠诚呈现显著影响 & 成立 \\
\hline
\end{tabular}

数据源：作者整理，2019 年 4 月

$\mathrm{H} 1$ 分析结果: 品牌形象对感知质量呈现显著影响。研究结果说明微信小程序的 品牌形象对用户对微信小程序的价值认识有正向的影响, 微信小程序的市场品牌形 象度越高, 用户在微信小程序中的质量认可程度则越高。因此微信小程序相关企业应 着重提升软件的市场品牌形象。市场品牌形象是其产品和服务质量的保障, 这种品牌 影响力带来的质量保障对用户能够产生正面影响力。用户在评价市场品牌形象较高 的小程序相关软件时，往往处于对品牌质量的信任度而增强其在质量的评价，进而提 升了对其质量的感知程度。 
$\mathrm{H} 2$ 结果分析: 品牌形象对预期质量呈现显著影响。研究结果说明微信小程序的 品牌形象, 与用户对其质量的心理预期程度有较大的关系。微信小程序良好的市场品 牌形象是其企业的无形资产, 能够增加产品和服务的附加值, 这种产品和服务的附加 值提升了用户对产品和服务的质量期待, 也加深了用户对微信小程序的质量信任度。 这充分说明了品牌形象对于企业市场竞争力的重要性, 因此小程序应该积极优化品 牌形象, 扩大品牌知名度和影响力, 通过媒体广告、公益活动、促销宣传和商业联合 等方式, 实现资源整合和品牌价值的增强。

$\mathrm{H} 3$ 结果分析：品牌形象对感知价值呈现显著影响。研究结果说明微信小程序的 品牌形象与用户对其价值的认可程度有直接关系, 当小程序在市场的影响力高, 竞争 能力强, 用户认可度高, 用户对所获取这一品牌的产品或服务时所付出的成本也认为 是值得的。因此微信小程序相关企业应该从提升品牌形象中着手, 只有提升品牌形 象, 才能增强产品或服务的附加值, 从而提升销售利润, 提升企业经营效益, 最终实 现综合竞争实力的提升。

H4 结果分析：品牌形象对顾客满意度呈现显著影响。研究结果说明小程序的品 牌形象与顾客满意度之间有直接的关系, 小程序的发展必须要提升品牌形象, 品牌形 象的提升与顾客满意度有正相关性, 也就是说品牌形象的建立不仅关乎到用户的感 知价值, 也关系到用户满意度的高低。市场品牌形象较高的小程序软件, 用户对其的 满意度评价更高, 这允分证实了企业无形资产和产品附加值, 对于提升用户消费体验 的作用。小程序要获得市场的尊重和信任, 必须要提升品牌形象, 建立广泛的品牌影 响力。

H5 结果分析: 预期质量对感知价值呈现显著影响。研究结果说明微信小程序用 户的预期质量对用户消费之后的消费价值感知有重要的影响。用户的预期质量是用 户消费之前对产品或者服务的心理期待, 感知价值是用户消费后对产品或服务的价 值认可, 这说明用户在对微信小程序的质量有高期待的前提下，对消费的价值认可也 相应提高，说明用户在对微信小程序质量期待较低的前提下，对消费的价值认可也相 应较低。因此微信小程序相关企业应该注重提升用户对微信小程序的质量预期, 提升 自身的品牌影响力和市场份额, 扩展服务内容, 提高市场口碑, 提升用户对微信小程 序的心理期待, 从而提高用户对其认可度。

H6 结果分析: 预期质量对感知质量呈现显著影响。研究结果说明微信小程序的 用户在消费的过程中，心理对质量的预期对消费之后对其质量的感知有显著影响。用 户在使用微信小程序之前, 对其产品和服务的质量期待较高, 其消费的心理活动为积 极的, 消费的过程中微信小程序能够满足用户的期望, 那么在实际消费之后对其质量 感知就越高。因此小程序相关企业应该在提升产品和服务的市场影响力, 创作产品质 量期望的同时，更应当注重对目标用户消费需求的挖掘，针对用户的消费，丰富产品 性能, 优化消费服务, 从根本上增加微信小程序用户的顾客满意度。

$\mathrm{H} 7$ 结果分析: 预期质量对顾客满意度呈现显著影响。研究结果说明微信小程序 用户对其产品和服务的质量心理预期，对最终的消费满意度评价有重要的影响。预期 质量是微信小程序用户对服务和产品的质量形成的心理期待, 这是用户对质量潜在 要求的体现。从顾客满意度的角度分析, 产品或服务在满足了使用者的消费需求时, 才会产生满意度, 也就是说顾客满意度与期望有直接联系。在微信小程序的消费中也 是如此, 用户对其质量期望与顾客的满意度之间有直接的关系, 因此微信小程序相关 企业应该着重从提升微信小程序用户心理质量期待的角度来提升顾客满意度, 既要 增加产品的宣传、信息, 也要实现对其宣传中的质量承诺, 建立用户与企业之间的信 
任, 进而提升顾客满意度。

H8 分析结果: 感知质量对感知价值呈现显著影响。研究结果说明微信小程序的 价值与其质量关系十分紧密, 这说明微信小程序的质量越高, 用户对其价值的感知程 度就越高, 也说明在微信小程序的消费过程中, 其服务质量越好, 用户对其价值的认 可程度越高。因此微信小程序相关企业应该着重从提升微信小程序的本身质量入手, 提升用户的感知质量, 从而提升顾客满意度。

H9 分析结果: 感知质量对顾客满意呈现显著影响。研究结果说明微信小程序用 户对价值的感知程度越高, 则对微信小程序的满意度越高, 也就是说用户对微信小程 序的价值越认可, 也就对微信小程序的产品和服务越满意。因此微信小程序的相关企 业应该在软件开发、售后服务、运营管理和用户服务方面的质量，有效提升用户对微 信小程序的价值认可, 从而增强软件的满意度。

H10 结果分析: 感知价值对顾客满意呈现显著影响。研究结果说明微信小程序 的用户对于其产品或服务的价值认可度与顾客满意度有密切的关系。当用户对于小 程序的价值认可, 认为享受小程序所提供的产品或服务与需要付出的成本之间是值 得的，对其产品和服务的价格感到认可，那么用户对小程序满意度则较高。因此微信 小程序的相关企业应该重点关注用户的感知价值, 加强目标市场分析, 加强用户群体 的分析。用户对产品和服务的价值感知能够影响其购买决定, 也能影响到用户对消费 活动的主观判断, 进而影响到企业市场影响力和核心竞争力, 从提升产品和服务的用 户感知价值出发来提升顾客满意度, 更有针对性。

H11 结果分析：顾客满意度对顾客忠诚度呈现显著影响。研究说明用户对微信 小程序的满意度能够影响到用户对微信小程序的忠诚度, 从二者的含义出发, 微信小 程序用户对产品或服务的直观感受与主观体验, 能够影响到用户的实际购买行为。因 此微信小程序的相关企业应该争取提升用户对其产品和服务的满意度, 进而维护市 场的占有率, 稳定客户群体的平衡, 在此基础上增加市场影响力, 提升综合竞争实力。

\section{2 路径分析研究结果综述}

本研究方法上, 基于 CCSI 模型, 对 CCSI 模型进行了修正假设。以微信小程序 作为研究对象, 对问卷调查所收集到的资料进行整理和分析, 验证路径分析模型的各 项假设，假设验证结果整理如表 34 及图 3 所示。

表 34. 路径分析研究假设验证结果表

\begin{tabular}{lll}
\hline 序号 & \multicolumn{1}{c}{ 研究假设 } & 验证结果 \\
\hline $\mathrm{H}_{\mathrm{I}}$ & 品牌质量对顾客忠诚度有显著影响 & 成立 \\
$\mathrm{H}_{\mathrm{II}}$ & 品牌质量通过顾客满意对顾客忠诚有显著影响 & 成立 \\
$\mathrm{H}_{\mathrm{III}}$ & 品牌质量通过感知价值和顾客满意对顾客忠诚有显著影响 & 成立 \\
$\mathrm{H}_{\mathrm{IV}}$ & 品牌质量通过感知价值对顾客忠诚有显著影响 & 成立 \\
$\mathrm{H}_{\mathrm{V}}$ & 感知价值通过顾客满意对顾客忠诚有显著影响 & 成立 \\
$\mathrm{H}_{\mathrm{VI}}$ & 感知价值对顾客忠诚有显著影响 & 成立 \\
$\mathrm{H}_{\mathrm{VII}}$ & 顾客满意对顾客忠诚有显著影响 & 成立 \\
\hline
\end{tabular}

数据源：作者整理, 2019 年 4 月 


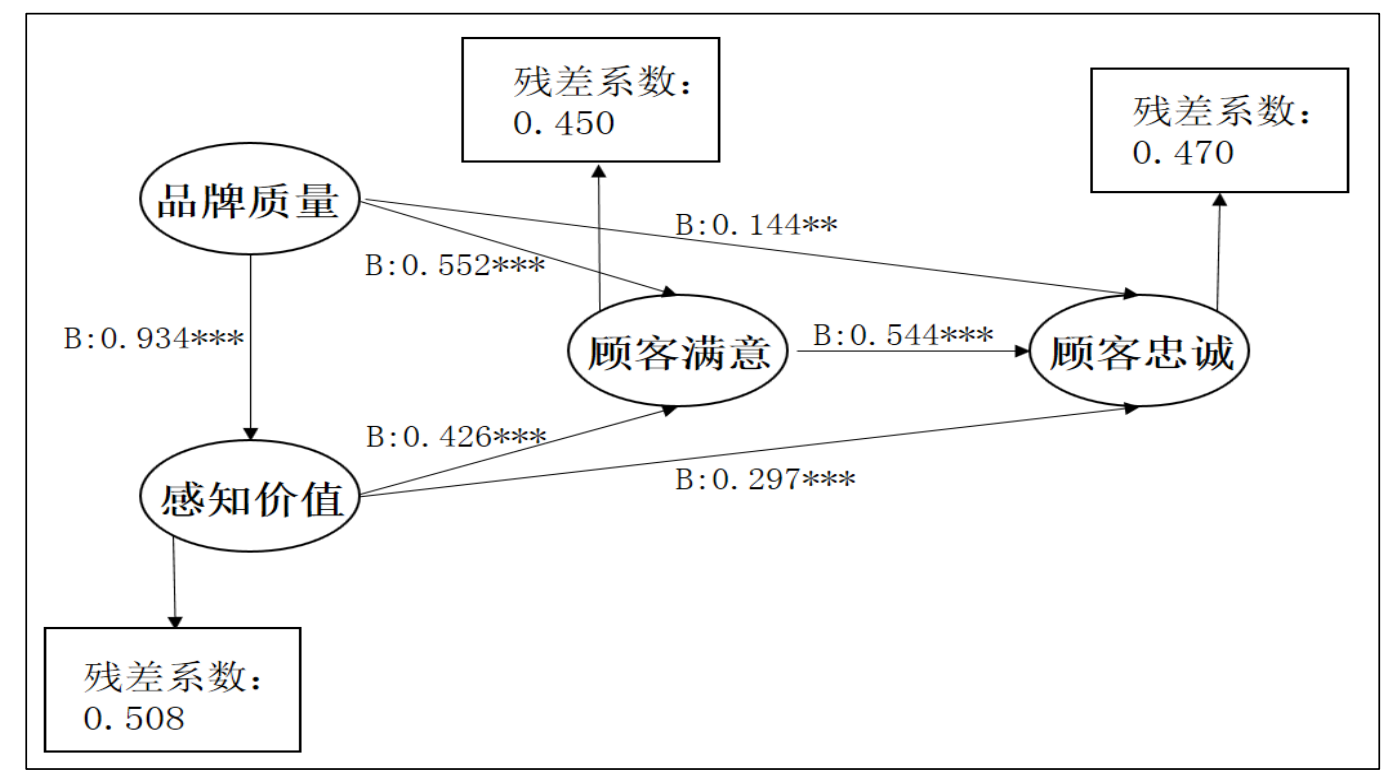

数据源：作者整理，2019 年 4 月

图 3. 路径分析研究结果整理图

$\mathrm{H}_{\mathrm{I}}$ 结果分析：品牌质量对顾客忠诚度有显著影响。品牌质量对顾客忠诚的路径 研究结果是 B 值为 0.144 , P 值为 0.007 小于 0.01 , 所以微信小程序的品牌质量对顾 客忠诚有正向的影响, 其中路径 B 值终值为 $0.144, \mathrm{P}<0.01$, 标记两颗星, 残差值为 0.470 。

$\mathrm{H}_{\mathrm{II}}$ 结果分析: 品牌质量通过顾客满意对顾客忠诚有显著影响。品牌质量对顾客 满意的研究结果是 $\mathrm{B}$ 值为 $0.552, \mathrm{P}$ 值为 0 小于 0.001 ; 顾客满意对顾客忠诚的研究 结果是 $\mathrm{B}$ 值为 $0.544, \mathrm{P}$ 值为 0 小于 0.001 , 该路径 $\mathrm{B}$ 值终值 $=0.552 \times 0.544=0.300, \mathrm{P}$ $<0.001$, 标记三颗星。

$\mathrm{H}_{\mathrm{III}}$ 结果分析: 品牌质量通过感知价值和顾客满意对顾客忠诚有显著影响。品牌 质量对感知价值的研究结果是 B 值为 $0.934, \mathrm{P}$ 值为 0 小于 0.001 ; 感知价值对顾客 满意的研究结果是 $\mathrm{B}$ 值为 $0.426, \mathrm{P}$ 值为 0 小于 0.001 ; 顾客满意对顾客忠诚的研究 结果是 $\mathrm{B}$ 值为 $0.544, \mathrm{P}$ 值为 0 小于 0.001 , 该路径 $\mathrm{B}$ 值终值 $=0.934 \times 0.426 \times 0.544=0.216$, $\mathrm{P}<0.001$, 标记三颗星。

H IV 结果分析: 品牌质量通过感知价值对顾客忠诚有显著影响。品牌质量对感知 价值的研究结果是 $\mathrm{B}$ 值为 $0.934, \mathrm{P}$ 值为 0 小于 0.001 ; 感知价值对顾客忠诚的研究 结果是 B 值为 $0.297, \mathrm{P}$ 值为 0 小于 0.001 , 该路径 $\mathrm{B}$ 值终值 $=0.934 \times 0.297=0.277, \mathrm{P}$ $<0.001$, 标记三颗星。

$\mathrm{HV}_{\mathrm{V}}$ 结果分析: 感知价值通过顾客满意对顾客忠诚有显著影响。感知价值对顾客 满意的研究结果是 $\mathrm{B}$ 值为 $0.426, \mathrm{P}$ 值为 0 小于 0.001 ; 顾客满意对顾客忠诚的研究 结果是 $\mathrm{B}$ 值为 $0.544, \mathrm{P}$ 值为 0 小于 0.001 , 该路径 $\mathrm{B}$ 值终值 $=0.426 \times 0.544=0.232, \mathrm{P}$ $<0.001$, 标记三颗星。

$\mathrm{H}_{\mathrm{VI}}$ 结果分析: 感知价值对顾客忠诚有显著影响。感知价值对顾客忠诚的路径研 究结果是 B 值为 0.297 , P 值为 0 小于 0.001 , 其中路径 B 值终值为 $0.297, \mathrm{P}<0.001$, 标记三颗星, 残差值为 0.508 。

HVII 结果分析：顾客满意对顾客忠诚有显著影响。顾客满意对顾客忠诚的路径 研究结果是 $\mathrm{B}$ 值为 $0.544, \mathrm{P}$ 值为 0 小于 0.001 , 其中路径 $\mathrm{B}$ 值终值为 $0.544, \mathrm{P}<$ 
0.001, 标记三颗星, 残差值为 0.450 。

综上分析结果, 可得路径分析 B 值结果整理如表 35：

表 35. 路径分析 B 值结果整理表

\begin{tabular}{lcc}
\hline \multicolumn{1}{c}{ 路径假设 } & B 值 & 残差 \\
\hline $\mathrm{H}_{\mathrm{I}}$ (品牌质量 $\rightarrow$ 顾客忠诚) & $0.144^{* *}$ & 0.470 \\
$\mathrm{H}_{\mathrm{II}}$ (品牌质量 $\rightarrow$ 顾客满意 $\rightarrow$ 顾客忠诚) & $0.300^{* * *}$ & - \\
$\mathrm{H}_{\mathrm{III}}$ (品牌质量 $\rightarrow$ 感知价值 $\rightarrow$ 顾客满意 $\rightarrow$ 顾客忠诚 $)$ & $0.216^{* * *}$ & - \\
$\mathrm{H}_{\mathrm{IV}}$ (品牌质量 $\rightarrow$ 感知价值 $\rightarrow$ 顾客忠诚) & $0.277^{* * *}$ & - \\
$\mathrm{H}_{\mathrm{V}}$ (感知价值 $\rightarrow$ 顾客满意 $\rightarrow$ 顾客忠诚) & $0.232^{* * *}$ & - \\
$\mathrm{H}_{\mathrm{VI}}$ (感知价值 $\rightarrow$ 顾客忠诚) & $0.297^{* * *}$ & 0.508 \\
$\mathrm{H}_{\mathrm{VII}}$ (顾客满意 $\rightarrow$ 顾客忠诚) & $0.544^{* * *}$ & 0.450 \\
\hline
\end{tabular}

数据源：作者整理，2019 年 4 月

***在 0.001 水平(双侧)上显著相关; ${ }^{* *}$ 在 0.01 水平(双侧)上显著相关 ; ${ }^{*}$ 在 0.05 水平(双侧)上显著相关

由表 35 可知, 在本次路径研究中, $\mathrm{H}_{\mathrm{I}}$ 路径 $\mathrm{B}$ 值最低, 为 0.144 , 且显著性为两 颗星 $(0.001<\mathrm{P}<0.01)$, 显著性同比其它路径也最不显著; $\mathrm{H}_{\mathrm{VII}}$ 路径 $\mathrm{B}$ 值最高, 为 0.544 , 且显著性为三颗星 $(\mathrm{P}<0.001)$, 说明品牌质量对顾客忠诚的直接路径影响分 量不够, 说明力度也不够, 顾客满意对顾客忠诚的直接路径影响分量较足, 说明度较 高。其它路径 B 值均在 0.2 0.3 之间, 说明力度也比较高。

\section{3 建议}

微信小程序截止目前 2019 年 4 月为止, 仅仅发展了两年零三个月, 并且这两年 零三个月其也依托了微信本身的庞大用户基础进行引流, 达到爆炸式的用户增长及 发展, 在此过程中, 对于用户的各方面体验, 微信小程序都还有提升空间。本研究给 小程序的开发管理者提供一些借鉴：

\section{(1) 细分用户群体}

根据基本的统计分析, 用户人口统计方面影响不大, 但使用频率呈现较极端化。 对于小程序来说, 应当适当提升用户粘度, 依托于微信的用户其面向的是所有用户， 并没有特定的用户群体的划分。

\section{(2) 把控用户喜好变化}

整体的满意度提升有利于小程序用户忠诚度; 多进行满意度相关的调研, 填补当 下小程序的调研空白, 有利于小程序在竞争中, 及时做出反应及应对, 增强小程序的 应变能力, 为特定商家打造特定使用人群的小程序。

\section{(3) 提供更多的引流导向}

为小程序提供更多的引流导向。小程序目前涉及全面，包括游戏、商户、平台等 各方面的企业或商户集体, 但就目前的情况来看, 大多数商户小程序仅仅靠商户自己 设计创立及推广, 许多使用者都是在需要的时候才去寻找并使用相关小程序, 平时并 不会自行发现有趣又实用的小程序, 这点在本调查中均有体现。小程序的开发与管理 者应该考虑特定的小程序有特定的使用时机, 将小程序的用户群体扩大以及用户体 验提高，是扩大市场提高竞争力的一种表现。 


\section{4 总结}

微信小程序在高速发展的互联网时代是一个全新的东西, 在上线的这两年零三 个月中，堪称完美的基础与发展环境使得它的发展如鱼得水。作为 APP 互补品的微 信小程序, 更应该在当下没有竞争者的环境下抓住机会, 迅速发展为庞然大物, 让未 来的潜在对手望而生畏。

在基于 CCSI 模型对微信小程序的满意度影响因素研究中, 本研究发现, 所有假 设均成立, 其中顾客满意度对顾客忠诚度呈现最显著的正向影响; 品牌形象对感知质 量呈现的正向影响最弱; 其它相关影响均强烈。所以, 基于 CCSI 模型研究结论, 未 来的微信小程序发展着眼点应该兼顾所有的影响因素, 提升顾客满意度, 从而提升顾 客忠诚度。

在研究验证路径分析模型中, 本研究发现所有假设均成立, 其中顾客满意度对顾 客忠诚度呈现最显著的正向影响; 品牌质量对顾客忠诚呈现的正向影响最弱; 其它路 径影响均偏弱。所以，基于模型修正后的路径分析研究结论，再次说明了未来的微信 小程序发展应该偏向于整体影响因素的全面发展, 提升顾客满意度, 以达到提升顾客 忠诚度的目的。

\section{参考文献}

1. 王海忠、王晶雪、何云 (2007)。品牌名、原产国、价格对感知质量与购买意向 的暗示作用。南开管理评论，6，19-25+32。

2. 王晨亮 (2004)。行业顾客满意度测评理论研究（未发表之硕士论文）。北京市： 首都经济贸易大学。

3. 汤万金、咸奎桐、郑兆红、康键（2009）。顾客满意测评理论与应用。北京; 中 国计量出版社。

4. 孙静芬 (2004) 。基于 CCSI 模型的手机行业 CSI 测评与改进研究（未发表之 硕士论文)。南京市：南京理工大学。

5. 李小军 (2006) 。企业品牌形象塑造研究（未发表之硕士论文）。湖南省：湘潭 大学。

6. 肖有康（2016）。旅游类手机 APP 用户满意度影响因素实证研究（未发表之硕 士论文)。湖北省：华中师范大学。

7. 吴绍玉(2012)基于 CCSI 的 $\mathrm{T}$ 市地铁乘客满意度研究(未发表之硕士论文)。 天津市：天津大学。

8. 佚名（2005）。中国标准化研究院顾客满意度测评中心成立。中国防伪，6，6262 。

9. 余庆 (2012)。晨希快递公司顾客满意度测评及提升研究（未发表之硕士论文）。 湖南省：中南大学。

10. 陈青（2012）。基于顾客价值的销售服务顾客满意度测评研究一以汽车 4S 店为 例。企业经济，31(7)，94-97。

11. 金宁（2009）。基于乘客满意度的城市轨道交通服务质量评价（未发表之硕士论 文)。吉林省：吉林大学。

12. 赵蓉辉（2014）。基于酒店文化评价指标的顾客满意度测评研究（未发表之硕士 论文)。湖南省：湘潭大学。

13. 常亚平、朱东红、张金隆（2009）。影响消费者重复网上购物行为因素的实证研 究一基于电子商务环境和网络商店因素的数据分析。管理评论, 4, 65-71。 
14. 董麦生（2013）。广州市房地产商住项目顾客满意度影响因素浅析（未发表之硕 士论文)。广州市：华南理工大学。

15. 蒋伟伟 (2007) 。基于 CCSI 模型的搜索引擎评价研究啨报科学, $11,1659-1663$ 。

16. 韩春鲜 (2015)。旅游感知价值和满意度与行为意向的关系。人文地理, 30(3), $137-144+150$ 。

17. Dardozo, R. N. (1965). An experimental study of consumer effort, expectation, and satisfaction. Journal of Marketing Research, 2, 244-249.

18. Tse, D. K. \& Wilton, P. C. (1988). Models of consumer satisfaction formation: An extension. Journal of Marketing Research, 25(2), 204-212.

19. Hunt, H. K. (1977). CS/D Overview and future research directions. Conceptualization and Measurement of Consumer Satisfaction and Dissatisfaction, MA: Marketing Science Institute, 455-488.

20. Kotlers P. (1990). Marketing management: Analysis, planning, implementation and control. NJ: Prentice Hall Press, 41-54.

21. Oliver, R. L. (1993). A conceptual model of service quality and service satisfaction: Compatible goals, different concepts. Advances in Services Marketing Management, 2, 65-85.

22. Parasuraman, A., Zeithaml, V. A. \& Berry, L. L. (1988). SERVQUAL: A multiple-item scale measuring consumer perceptions of service quality. Journal of Retailing, 64(1), 12-37.

23. Kotler, P. (1999). The marketing of leadership: A leader to leader guide. In On HighPerformance Organization: A Leader to Leader Guide, NY: Jossey-Bass, 22-27.

24. Solomon, M. R. (1991). Consumer behavior: Buying, having, and being. Boston: Allyn and Bacon.

25. Westbrook, R. A. (1980). Intrapersonal affective influences on consumer satisfaction with products. Journal of Consumer Research, 7(1), 49-54. 